ARTIGOS

\title{
Considerações sobre os indicadores de formação docente no Brasil $^{1}$
}

\section{Considerations on Brazilian Teacher Training Indicators}

Roseli Constantino Schwerz ${ }^{(i)}$

Natalia Neves Macedo Deimling (ii)

Cesar Vanderlei Deimling (iii)

Daniele Cristina da Silva (iv)

(i) Universidade Tecnológica Federal do Paraná - UTFPR, Campo Mourão, PR, Brasil.

https://orcid.org/0000-0001-5507-3117, rconstantino@utfpr.edu.br.

(ii) Universidade Tecnológica Federal do Paraná - UTFPR, Campo Mourão, PR, Brasil. https://orcid.org/0000-0001-8394-3132, natanema@gmail.com.

(iii) Universidade Tecnológica Federal do Paraná - UTFPR, Campo Mourão, PR, Brasil. https://orcid.org/0000-0002-1554-0099, cdeimling@utfpr.edu.br.

(iv) Faculdade de Tecnologia de Campinas - FATEC, Campinas, SP, Brasil. https://orcid.org/00000001-5624-9321, danielecristina.cs@gmail.com.

Resumo:
Neste artigo buscamos analisar e tecer algumas considerações a respeito dos
indicadores divulgados pelo Instituto Nacional de Estudos e Pesquisas
Educacionais Anísio Teixeira/Ministério da Educação sobre a formação de
professores nos cursos de licenciatura no Brasil. Os dados selecionados para análise
e discussão foram retirados das sinopses estatísticas fornecidas entre os anos de
2001 e 2015 e compreendem o número de vagas oferecidas, de ingressos e de
concluintes por cursos de graduação. A partir da análise dos dados, podemos
observar que, embora o número de vagas tenha aumentado no período, os cursos
de licenciatura ainda apresentam baixa procura e muitas vagas ociosas. Os cursos de
Física têm o menor número de concluintes em comparação com os outros cursos
analisados. Essa realidade pode ser influenciada por diferentes fatores, entre os quais
a baixa procura por cursos de licenciatura e a alta taxa de evasão.
Palavras-chave: formação de professores, licenciatura, ensino superior, evasão

${ }^{1}$ Normalização, preparação e revisão textual: Douglas Mattos (Tikinet) - revisao@tikinet.com.br 


\section{pro.posıções}

http://dx.doi.org/10.1590/1980-6248-2017-0199

\section{Abstract:}

In this paper, we analyze the data from Instituto Nacional de Estudos e Pesquisas Educacionais Anísio Teixeira/Ministério da Educação on teacher training in Brazill. The data selected for analysis were taken from the synopses provided between 2001 and 2015 and comprise the number of available places, admissions and graduates by undergraduate courses. From the data analysis, we can observe that the number of places available at universities has increased during the period, but teacher-training courses still present low demand and many unfilled places. Physics courses have the lowest number of graduates compared to other courses analyzed. This reality may be influenced by many factors such as high evasion rate and low demand for teacher-training courses.

Keywords: teacher education, teacher-training courses, higher education, evasion

\section{Introdução}

Nas últimas décadas - especialmente a partir de 1990 -, têm-se realizado algumas reformas políticas e sociais aliadas a sugestões e estratégias advindas de organismos multilaterais, como o Banco Mundial, o Fundo Monetário Internacional e a Organização para a Cooperação e Desenvolvimento Econômico (OCDE), para a educação em todo o mundo, as quais atingem especialmente os países considerados em desenvolvimento (Ferreira, 2011; Maués, 2011; Mazzeu, 2009; Shiroma, Moraes, \& Evangelista, 2007; entre outros). As recomendações desses organismos multilaterais para a educação e, neste caso particular, para a formação docente, estão presentes nas políticas de vários países, inclusive no Brasil, apesar da resistência de alguns movimentos sociais e entidades acadêmicas. Trata-se de ações compensatórias que, ao invés de solucionar a falta de professores, acabam por agravar ainda mais o problema da formação, das condições de trabalho e da inserção e permanência dos professores na profissão.

Considerando a carência de professores formados no Brasil, e em consonância com a reforma educacional que vinha se delineando desde 1990, uma comissão instituída pelo Conselho Nacional de Educação/Ministério da Educação (CNE/MEC) elaborou, em 2007, o relatório Escassez de professores no Ensino Médio: propostas estruturais e emergenciais, que traz uma compilação de dados divulgados pelo Instituto Nacional de Estudos e Pesquisas Educacionais Anísio Teixeira (Inep/MEC), pela Confederação Nacional dos Trabalhadores em Educação e 


\section{pro.posições}

$e$-ISSN 1980-6248

http://dx.doi.org/10.1590/1980-6248-2017-0199

pela OCDE (Ruiz, Ramos, \& Hingel, 2007). O déficit apresentado pelo relatório naquele ano era de 479.906 professores para as séries finais do ensino fundamental e de 246.085 professores para o médio. Assim, seria preciso cobrir cerca de 746 mil postos de trabalho docente no país. Todavia, o mesmo documento apresentava dados preocupantes sobre a formação de professores, mostrando a grande evasão existente nos cursos de licenciatura, especialmente nas áreas de Física, Química e Matemática, bem como o baixo número de professores formados nesses cursos (Ruiz, Ramos, \& Hingel, 2007).

Tendo como base esse quadro, o relatório apresentou algumas soluções emergenciais para o atendimento da necessidade de professores para a Educação Básica, tais como o incentivo para professores aposentados voltarem a dar aulas nas disciplinas em que há maior carência de docentes formados; o retardamento das aposentadorias dos professores de Ensino Médio - por meio de incentivos fiscais ou financeiros; a contratação de profissionais não licenciados como docentes da Educação Básica; a contratação de professores estrangeiros em disciplinas específicas; a criação de bolsas de estudos para alunos egressos de escolas públicas cursarem licenciatura na rede privada; o uso complementar das telessalas, especialmente para o ensino das disciplinas do Ensino Médio; e o aproveitamento, em caráter emergencial, de alunos de licenciatura como docentes por meio de bolsas de iniciação à docência (Ruiz, Ramos, \& Hingel, 2007).

Algumas dessas recomendações foram adotadas e incorporadas na política educacional brasileira (Ferreira, 2011; Maués, 2011; Mazzeu, 2009; Shiroma et al., 2007) e seguem até os dias atuais, podendo ser observadas também nas atuais reformas propostas para a Educação Básica. Diferentes programas federais têm sido criados para tentar solucionar - ou dissimular - o problema da formação docente no país, muitos deles pontuais e/ou emergenciais. Todavia, conforme argumenta Freitas (2007), a escassez de professores para a Educação Básica apontada pelo relatório do CNE não pode ser caracterizada como um problema exclusivamente emergencial, mas, sim, como um problema crônico, produzido historicamente pela retirada da responsabilidade do Estado pela manutenção da educação pública, gratuita e de qualidade, bem como da formação de seus educadores. Para a autora, longe de equacionar o problema da falta de professores para educação básica na direção de uma política de valorização da formação docente, as alternativas apresentadas pelo relatório podem levar ao aligeiramento e à flexibilização dessa formação. 


\section{pro.posıções}

$e$-ISSN 1980-6248

http://dx.doi.org/10.1590/1980-6248-2017-0199

Com essas estratégias, o país busca, ao mesmo tempo, suprir a necessidade de formação de professores para a Educação Básica e delinear uma política que adapte a formação e a atuação do professor ao novo modelo de sociedade que se busca estabelecer, em consonância com as exigências internacionais. Essa necessidade em suprir a demanda por formação docente foi intensificada com a aprovação da Emenda Constitucional n. 59, de 11 de novembro de 2009, que dá nova redação aos incisos I e VII do art. 208 da Constituição Federativa do Brasil. Tal emenda prevê a universalização do ensino de 4 a 17 anos, tornando o Ensino Médio obrigatório. Com essa ampliação da obrigatoriedade, seria necessário contratar mais professores para atuação na Educação Básica.

Todavia, de acordo com dados da auditoria realizada no ano de 2014 pelo Tribunal de Contas da União (TCU) em parceria com os tribunais de contas estaduais (TCU, 2014), há no Brasil um déficit estimado de 32.700 professores com formação específica nas 12 disciplinas obrigatórias que, até então, compõem o currículo do ensino médio. Física aparece como a disciplina com maior carência - mais de 9 mil professores - e é o único caso com déficit em todos os estados. Em seguida vem a disciplina de Química, representando 15\% de déficit de professores em 25 estados (Deimling, 2014). Entre outros motivos, esses dados podem ser justificados devido ao fato de que, segundo Gatti \& Barreto (2009), ao saírem desses cursos, os estudantes geralmente encontram melhores ofertas de trabalho fora da docência. Os dados apresentados por essa auditoria do TCU se somam à estatística apresentada pelo CNE em 2007 e evidenciam a alarmante escassez de professores para a Educação Básica.

Considerando todos esses aspectos, buscamos, neste artigo, analisar e tecer algumas considerações a respeito dos indicadores divulgados pelo Inep/MEC sobre a formação de professores nos cursos de licenciatura no Brasil, tendo como base o número de cursos e de vagas oferecidas e de ingressantes e egressos desses cursos. Para essa análise, tomamos como base também alguns importantes estudos e pesquisas realizados sobre o tema, que discutem, entre outros aspectos, os impactos dessas reformas políticas na formação e carreira docente no Brasil. 


\section{pro.posıções}

http://dx.doi.org/10.1590/1980-6248-2017-0199

\section{$e$-ISSN 1980-6248}

\section{Método e procedimentos}

Este trabalho tem como base o método quanti-qualitativo de pesquisa, no qual dados estatísticos são utilizados como base para a descrição, compreensão, análise e interpretação dos resultados. Os dados apresentados e discutidos neste artigo fazem parte das sinopses divulgadas anualmente pelo Inep (2017). Estas sinopses apresentam informações sobre todos os cursos de graduação - sejam eles bacharelados, licenciaturas ou tecnologias. Os dados selecionados para análise neste trabalho foram retirados das sinopses fornecidas entre os anos de 2001 e 2015 e compreendem os seguintes indicadores: (i) número de vagas oferecidas e ingressos por vestibular e outros processos seletivos, por cursos de graduação presenciais e a distância, e (ii) número de concluintes, por cursos de graduação presenciais e a distância.

Alguns dos dados apresentados pelo Inep categorizam os cursos de graduação em grupos e subgrupos. Como o objetivo deste artigo consiste numa breve análise do cenário da formação docente no Brasil, optamos por trabalhar apenas com alguns dados referentes ao subgrupo "Formação de professor em matérias específicas", dentro do grupo "Educação". A escolha por esse subgrupo se justifica pelo alto déficit de professores com formação específica nas 12 disciplinas obrigatórias que compõem o currículo do Ensino Médio, conforme dados do TCU (TCU, 2014) apresentados anteriormente, na Introdução. Foram selecionados para análise os dados relativos aos cursos de licenciatura em Biologia, Filosofia, Física, Geografia, História, Letras, Matemática e Química. Assim, quando se mencionam "cursos de licenciatura”, refere-se a dados relacionados a estes oito cursos. Esta seleção foi realizada considerando todos os cursos deste subgrupo que tiveram todos os seus dados disponibilizados em todas as sinopses no intervalo de tempo delimitado pela pesquisa.

As informações referentes ao curso de Letras são apresentadas de forma agrupada diferentemente das planilhas originais divulgadas pelo Inep. Essa organização foi necessária devido a algumas nomenclaturas utilizadas variarem nas sinopses ao longo dos anos. Por exemplo, no ano de 2014, os dados são apresentados em seis divisões - (i) Letras, (ii) Linguística, (iii) Língua/literatura estrangeira clássica, (iv) Língua/literatura estrangeira moderna, (v) Língua/literatura vernácula (português) e (vi) Língua/literatura vernácula e língua estrangeira moderna. No entanto, no ano de 2008, são apresentadas apenas quatro divisões: (i) Letras, (ii) Língua/literatura estrangeira moderna, (iii) Língua/literatura vernácula (português) e (iv) Língua/literatura vernácula e língua estrangeira moderna. A segunda e terceira divisões 


\section{pro.posıções}

http://dx.doi.org/10.1590/1980-6248-2017-0199

\section{$e$-ISSN 1980-6248}

apresentadas em 2014 não são mencionadas. Portanto, considerando essas alterações de nomenclatura nas sinopses, que também ocorreram em outras sinopses, optamos por agrupar os dados conforme apresentados em 2014, que é mais abrangente, e denominamos este grupo de "Formação de professores em Letras".

Os resultados desta pesquisa são apresentados do seguinte modo: (i) dados dos cursos de licenciatura selecionados por ano; (ii) dados de todos os outros cursos (todos os cursos, com exceção dos cursos de licenciatura selecionados) por ano; (iii) dados específicos dos cursos de licenciatura em Física por ano; e (iv) comparação entre os cursos, levando-se em conta os valores obtidos no total dos 15 anos analisados. A partir da manipulação dos dados, definimos os indicadores "taxa de ocupação das vagas disponíveis" (razão entre o número de ingressos e o número de vagas) e "razão concluintes/ingressos". Os dados foram analisados e discutidos à luz de alguns importantes estudos e pesquisas realizados nos últimos anos sobre o tema. Nessa análise levaram-se em conta aspectos tidos como relevantes para a discussão das possíveis causas da carência de professores e da evasão nos cursos de licenciatura no Brasil.

Por uma questão de apresentação, utilizamos algumas abreviações dos indicadores ao longo do texto e das figuras. Em relação à modalidade de ensino, designamos pela letra $\mathrm{P}$ os cursos presenciais e pela letra D os cursos a distância. Quando o dado for a soma de números do ensino presencial e do ensino a distância, designamos pela letra $T$ (total). Vagas, ingressantes, concluintes e taxas de ocupação foram designados por V, I, C e I/V respectivamente. Assim, por exemplo, temos as seguintes abreviações: vagas presenciais (VP), vagas a distância (VD), vagas totais (VT), e taxa de ocupação totais (IT/VT).

Os dados designados pela letra $\mathrm{L}$ indicam dados referentes à soma de dados relativos a todos os cursos de licenciatura selecionados neste trabalho, ao longo dos 15 anos em análise. Portanto, utilizamos as abreviações VL, IL e CL que são todas as vagas disponíveis, os ingressantes e concluintes em todos os cursos de licenciatura selecionados ao longo de $2001 \mathrm{e}$ 2015.

Os indicadores do Inep apresentam números totais de vagas, ingressantes e concluintes de todos os cursos considerando todas as habilitações abrangidas nas sinopses (licenciaturas, bacharelados e tecnologias). Com o intuito de ampliar a análise destes números foram subtraídos os números referentes aos cursos de licenciatura selecionados e denominados de "outros cursos". Assim, como exemplo, IO é "ingressantes de outros cursos". 
Como os valores absolutos dos dados do grupo "outros cursos" são muito superiores aos dados do grupo "cursos de licenciatura selecionados", os números de vagas e ingressantes foram normalizados pelo respectivo número apresentado em 2001 com o objetivo de se comparar os comportamentos das variáveis em análise. Estes dados normalizados são indicados pela letra "n" minúscula ao final da abreviação dos dados. Por exemplo, IOn representa o número normalizado de ingressos em outros cursos.

\section{Resultados e discussões}

Tendo em vista os objetivos deste estudo e o referencial teórico que o norteia, apresentamos nesse item a análise e a discussão dos indicadores disponibilizados pelo Inep sobre a formação de professores nos cursos de licenciatura no Brasil.

A Figura 1 traz o número de ingressantes, número de vagas e a taxa de ocupação destas vagas nos cursos de licenciatura selecionados e nos outros cursos, considerando o ensino presencial e a distância.

Figura 1 - Comportamento da taxa de ocupação de vagas, do número de vagas e do número de ingressantes nos cursos de licenciatura selecionados e em outros cursos, 2001-2015

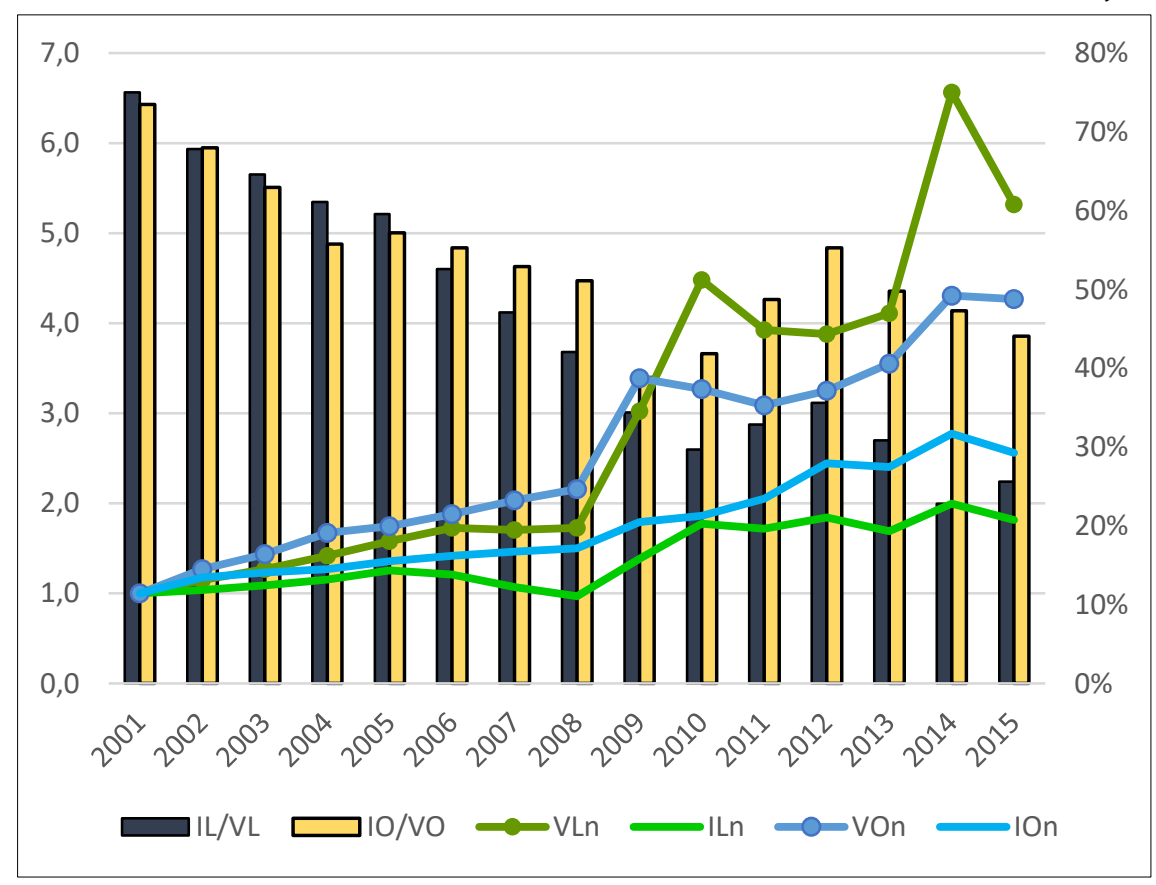

Nota: eixo esquerdo: vagas e ingressantes dos cursos de licenciatura selecionados (VLn e ILn) e vagas e ingressantes nos outros cursos (VOn e IOn), ambos normalizados em relação ao ano de 2001; eixo direito: taxa de ocupação das vagas dos cursos de licenciatura selecionados (IL/VL) e dos outros cursos (IO/VO). Fonte: elaborado a partir de Inep (2017). 


\section{pro.posıções}

De modo geral, nota-se que em ambos os casos a taxa de ocupação dos cursos no nível superior sofreu queda desde 2001. O decréscimo é praticamente contínuo até 2009. Houve crescimento apenas entre 2010 e 2012, seguido de nova queda.

Analisando os dois grupos, é possível afirmar que a taxa de ocupação das vagas nos cursos de licenciatura selecionados foi maior que nos outros cursos entre 2001 e 2005, com média de 65\% e 62\% das vagas ocupadas, respectivamente. Todavia, entre 2006 e 2015 observa-se uma inversão. Os cursos de licenciatura selecionados só tiveram 32\% de suas vagas ocupadas, enquanto os demais cursos apresentaram $48 \%$ de preenchimento.

Sobre o número de vagas, nota-se que, proporcionalmente, as licenciaturas selecionadas tiveram maior crescimento, principalmente a partir de 2010. Antes esse crescimento era ligeiramente menor. No entanto, analisando o número de ingressos, houve pouca alteração para este grupo. Nos outros cursos, o crescimento do número de vagas foi menos expressivo, mas o número de ingressantes teve um aumento de aproximadamente 30\% entre 2010 e 2015.

Considerando que a procura pelos cursos de licenciatura selecionados se manteve constante e que o número de ingressos totais aumentou, considera-se que estes cursos se tornaram, a partir de 2006, os preferidos pelos estudantes de modo geral. Ou seja, estes dados demonstram que os outros cursos, que em sua grande maioria são de bacharelado e tecnologia, estão sendo mais escolhidos pela maior parte dos ingressantes.

$\mathrm{Na}$ Figura 2 são apresentados números discriminados pelo tipo de modalidade de ensino - presencial e a distância - apenas dos cursos de licenciatura selecionados. 
Figura 2 - Comportamento da taxa de ocupação de vagas, do número de vagas e do número de ingressantes nos cursos de licenciatura selecionados de acordo com a modalidades de ensino (presencial e a distância), 2001-2015

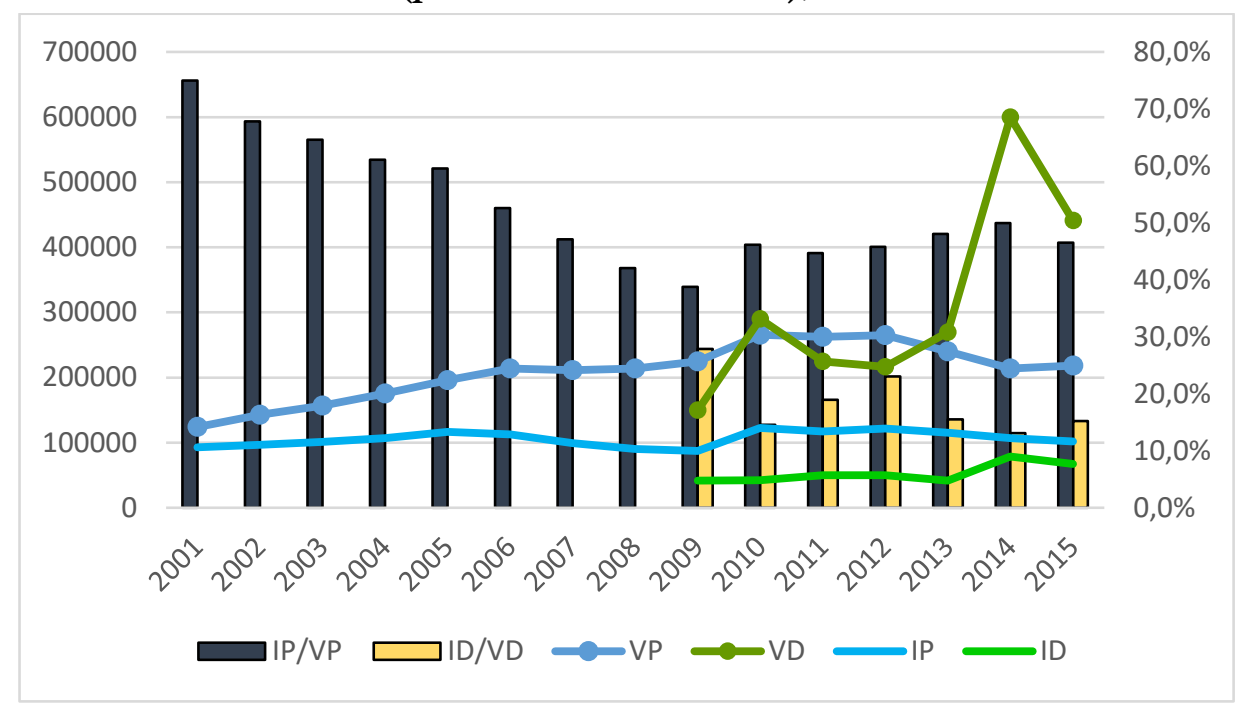

Nota: eixo esquerdo: vagas presenciais (VP), vagas a distância (VD), ingressantes presenciais (IP) e ingressantes a distância (ID); eixo direito: taxa de ocupação das vagas presenciais (IP/VP) e a distância (ID/VD). Todos os dados se referem aos cursos de licenciatura selecionados.

Fonte: elaborado a partir de Inep (2017).

Analisando os dados, a Figura 2 indica que, de modo geral, houve aumento de vagas ofertadas ao longo dos anos analisados. Se somarmos as duas modalidades, o número de vagas totais em 2015 cresceu aproximadamente $432 \%$ em relação a 2001, o que equivale a mais de cinco vezes o valor referente a 2001. Esse rápido crescimento no número de vagas totais, especialmente a partir de 2009, pode ser justificado pelo expressivo crescimento do número de vagas de cursos a distância entre os anos de 2009 e 2015. Entre os anos de 2001 e 2015, as VP aumentaram 76,0\%, sendo que no ano de 2015 as VD já correspondiam a 41,2\% das VT. Se limitarmos os dados entre os anos de 2009 e 2015, verificaremos que praticamente não houve mudanças nesta modalidade, tendo sido a variação de aproximadamente 195\%. Considerando que os dados relativos à educação a distância $(\mathrm{EaD})$ passaram a ser divulgados apenas a partir de 2009, trata-se de um crescimento bastante significativo dessa modalidade de ensino em relação ao número de vagas em cursos presenciais, analisado num período maior. Em 2009, as VD correspondiam a 40,0\% das VT, no entanto, a partir de 2013, os cursos a distância passaram a oferecer mais vagas do que os cursos presenciais. Em 2015, por exemplo, as VD correspondem a $66,9 \%$ de todas as vagas ofertadas no ano. 


\section{pro.posıções}

http://dx.doi.org/10.1590/1980-6248-2017-0199

$e$-ISSN 1980-6248

Além da inserção dos dados dos cursos EaD nas sinopses a partir de 2009, outro fator que pode ter influenciado este quadro se refere às políticas de criação e ampliação de vagas nas instituições públicas de Ensino Superior, elaboradas pelo governo federal nos últimos 10 anos. Um exemplo é o Programa de Apoio a Planos de Reestruturação e Expansão das Universidades Federais (Reuni), instituído pelo Decreto n ${ }^{\circ}$ 6.096, de 24 de abril de 2007, o qual possibilitou a criação de novas instituições de Ensino Superior e firmou com as já existentes um acordo de ampliação de vagas nos cursos de graduação. Neste período, o Reuni, ao lado do Programa de Financiamento Estudantil (Fies) e da Lei no 12.711/2012 (referente às cotas para ingresso nas universidades públicas) - também criados nesse período -, foi o responsável por um aumento expressivo na oferta de vagas em instituições públicas federais de Ensino Superior, bem como na criação de universidades e institutos federais em todo o Brasil.

A taxa de ocupação por vaga na modalidade presencial foi de 50,9\%, durante os 15 anos, e no período 2009-2015 a taxa de ocupação ficou em torno de 45,6\%, muito superior à modalidade $\mathrm{EaD}$, que teve em média 17,0\% das vagas ocupadas. Essa diferença entre as duas modalidades se justifica pelo fato de os cursos $\mathrm{EaD}$ (entre os cursos de licenciatura selecionados) terem ofertado mais vagas. No entanto, nota-se pela Figura 2 que o número de ingressantes ainda é menor que nos cursos presenciais. Deste modo, há um número muito maior de vagas ociosas na $\mathrm{EaD}(83,0 \%)$ do que no ensino presencial $(54,6 \%)$.

Outro ponto importante no número de licenciados nestes cursos selecionados se refere ao número de concluintes ao longo destes 15 anos. Estes dados são apresentados na Tabela 1, com distinção da modalidade de ensino. 


\section{pro.posições}

http://dx.doi.org/10.1590/1980-6248-2017-0199

$e$-ISSN 1980-6248

Tabela 1 - Número de vagas, de ingressantes e de concluintes nos cursos de licenciatura selecionados, 2001-2015

\begin{tabular}{|c|r|r|r|r|r|r|}
\hline Ano & VT & \multicolumn{1}{c}{ IT } & CP & CD & CT & CT/IT \\
\hline $\mathbf{2 0 0 1}$ & 123.996 & 93.012 & 32.052 & - & 32.052 & $34,5 \%$ \\
$\mathbf{2 0 0 2}$ & 142.558 & 96.656 & 48.217 & - & 48.217 & $49,9 \%$ \\
$\mathbf{2 0 0 3}$ & 157.080 & 101.427 & 56.830 & - & 56.830 & $56,0 \%$ \\
$\mathbf{2 0 0 4}$ & 175.492 & 107.210 & 62.552 & - & 62.552 & $58,3 \%$ \\
$\mathbf{2 0 0 5}$ & 195.614 & 116.545 & 71.562 & - & 71.562 & $61,4 \%$ \\
$\mathbf{2 0 0 6}$ & 213.987 & 112.530 & 68.666 & - & 68.666 & $61,0 \%$ \\
$\mathbf{2 0 0 7}$ & 211.006 & 99.348 & 65.074 & - & 65.074 & $65,5 \%$ \\
$\mathbf{2 0 0 8}$ & 213.964 & 90.032 & 63.833 & - & 63.833 & $70,9 \%$ \\
$\mathbf{2 0 0 9}$ & 374.717 & 128.953 & 62.488 & 19.908 & 82.396 & $63,9 \%$ \\
$\mathbf{2 0 1 0}$ & 555.455 & 164.874 & 71.175 & 21.484 & 92.659 & $56,2 \%$ \\
$\mathbf{2 0 1 1}$ & 486.582 & 159.854 & 67.063 & 17.523 & 84.586 & $52,9 \%$ \\
$\mathbf{2 0 1 2}$ & 480.956 & 171.190 & 61.316 & 16.284 & 77.600 & $45,3 \%$ \\
$\mathbf{2 0 1 3}$ & 509.590 & 157.238 & 56.587 & 15.615 & 72.202 & $45,9 \%$ \\
$\mathbf{2 0 1 4}$ & 813.796 & 185.667 & 56.969 & 19.727 & 76.696 & $41,3 \%$ \\
$\mathbf{2 0 1 5}$ & 659.370 & 168.688 & 58.823 & 18.957 & 77.780 & $46,1 \%$ \\
\hline Total & 5.314 .163 & 1.953 .224 & 903.207 & 129.498 & 1.032 .705 & $52,9 \%$ \\
\hline
\end{tabular}

VT: número de vagas totais; IT: ingressantes totais; CP: concluintes presenciais; CD: concluintes a distância; CT: concluintes totais; CT/IT: razão concluintes/ingressantes de todos os cursos de licenciatura selecionados ${ }^{2}$.

Fonte: elaborado a partir de Inep (2017).

Assim como o número de vagas e o número de ingressos nos cursos de licenciatura analisados cresceram, o número de concluintes também apresentou aumento, no entanto, de modo mais discreto. De acordo com a Figura 2, o número de ingressos em 2015 cresceu 81,4\% em relação a 2001, enquanto o número de concluintes correspondeu a 142,7\%, resultando em aproximadamente um milhão de licenciados formados ao longo desses 15 anos. Comparando a evolução de IT e CT, é possível verificar que a razão CT/IT sofreu mudanças de comportamento ao longo destes 15 anos (crescimento até 2009 seguido de decréscimo), com percentuais sempre maiores que o de 2001.

Em contrapartida, na Figura 2 é possível observar que, apesar de apresentar um significativo aumento - principalmente a partir de 2009 -, as vagas estão sendo cada vez menos preenchidas. Entre os anos de 2001 e 2015, nota-se um aumento significativo no número de vagas ociosas. Em 2001, este valor era de 25,0\%, chegando, em 2015, ao patamar de 74,4\% de vagas desperdiçadas. A partir dos dados apresentados, é possível observar que, ao longo desses 15 anos, foram oferecidas mais de 5 milhões de vagas; todavia, o número de ingressos não

${ }^{2}$ Entre 2001 e 2008, os dados fornecidos eram apenas referentes ao ensino presencial. 


\section{pro.posıções}

http://dx.doi.org/10.1590/1980-6248-2017-0199

chegou a 2 milhões. Ou seja, mais de $60 \%$ das vagas oferecidas - mais de 3 milhões - não foram preenchidas. Isso evidencia um baixo aproveitamento de vagas nos cursos de licenciatura analisados no período, o que indica a necessidade de que sejam conduzidas ações que favoreçam o melhor aproveitamento dessas vagas no Ensino Superior.

Não se pode negar o fato de que, quanto mais vagas ofertadas e mais instituições de Ensino Superior existirem distribuídas por todo o território brasileiro, maior será o acesso dos estudantes aos diferentes cursos de graduação. Porém, os números apresentados neste trabalho indicam que, apesar do significativo crescimento do número de vagas nos cursos de licenciatura, sua ocupação ficou aquém do esperado. Como já discutimos, apesar de se configurar como uma conquista, o aumento de vagas nesses cursos não garante, por si só, sua procura e ocupação por parte dos estudantes. Essa constatação nos permite inferir que outros fatores além do número de vagas oferecidas podem influenciar a baixa procura dos estudantes pelos cursos de licenciatura, entre os quais podemos destacar a baixa atratividade e valorização da carreira profissional docente.

Diferentes estudos e pesquisas sobre formação de professores (Deimling, 2014; Gatti, Barreto, \& André, 2011; Oliveira, 2011; Tardif, 2012; Tartuce, Nunes, \& Almeida, 2010) discutem sobre as condições objetivas e subjetivas relacionadas à formação e à carreira docente, bem como sobre as influências dessas condições na escolha e permanência na profissão. De acordo com esses estudos, a complexidade da docência, aliada à precarização das condições de trabalho, à sensação de insegurança e desamparo da profissão e aos baixos salários, tem prejudicado a autoestima social e profissional dos professores e resultado em baixa atratividade pela carreira. A união desses fatores resulta no questionamento dos professores sobre a permanência ou não na carreira, no descomprometimento pessoal em relação à profissão e no abandono da profissão por uma grande parcela de docentes, bem como daqueles que ainda estão em processo de formação.

Dentre os aspectos relacionados à precarização das condições de trabalho, a questão salarial parece ser um dos fatores que mais chamam atenção. Vaillant (2006), ao analisar a profissão docente na América Latina, identifica alguns pontos comuns entre os diferentes países que compõem esse contexto: entorno profissional que dificulta reter os bons professores na docência; poucos estímulos para que a profissão seja a primeira opção na carreira; condições de trabalho inadequadas; sérios problemas na remuneração e na carreira. De acordo com a autora, 


\section{pro.posıções}

http://dx.doi.org/10.1590/1980-6248-2017-0199

\section{$e$-ISSN 1980-6248}

os níveis salariais da profissão docente nos países latino-americanos são, de modo geral, muito baixos em relação aos países considerados desenvolvidos, fator que tem dificultado tanto a escolha dos jovens pela profissão quanto a permanência dos professores na carreira. $\mathrm{O}$ mesmo pode ser identificado no estudo realizado por Louzano, Rocha, Moriconi, \& Oliveira (2010), o qual, ao evidenciar a importância da formação docente como um dos elementos essenciais para a qualidade da educação básica, indica que os salários iniciais da carreira são pouco competitivos em relação a outras ocupações que têm se apresentado mais vantajosas financeiramente aos estudantes egressos do Ensino Médio ou mesmo dos cursos de licenciatura. A essa baixa remuneração soma-se o baixo status social da carreira em relação a outras profissões que exigem o mesmo nível de escolarização.

Gatti \& Barreto (2009), em um estudo que analisa o perfil e a carreira docente no Brasil, também apontam que o salário inicial dos professores tem sido, no geral, baixo quando comparado a outras profissões que exigem o mesmo nível de escolarização, fator que, aliado ao desprestígio profissional e à precarização das condições de trabalho e de carreira, tem influenciado negativamente a procura por esse trabalho entre os jovens. Nesse mesmo estudo, tendo como fonte de dados o questionário socioeconômico do Exame Nacional de Desempenho de Estudantes de 2005 respondido por estudantes de licenciatura, as autoras indicam que entre os estudantes que optam pelo curso de Pedagogia, 65,1\% (25.625 alunos) atribuem a escolha ao fato de querer ser professores; em contrapartida, entre os estudantes que optam pelas demais licenciaturas (em áreas específicas), esse percentual cai para 48,6\% (47.469 alunos). As autoras indicam também o percentual de estudantes que optam por seguir carreira acadêmica em lugar da docência na Educação Básica. Para os cursos de licenciatura em áreas específicas, esse percentual corresponde a 33,3\%, enquanto para os cursos de Pedagogia o percentual é de $31,8 \%$.

Assim, com base nos estudos que vêm sendo realizados e nos dados analisados neste trabalho, podemos inferir que o problema da falta de professores em nosso país não está relacionado, necessariamente, à escassez de vagas nos cursos de graduação. Certamente, o número de vagas pode e deve ser ampliado, todavia, o incentivo à carreira do magistério não depende apenas de políticas de ampliação do acesso ao Ensino Superior, mas também e, acima de tudo, de políticas de valorização do trabalho e da carreira docente, o que implica necessariamente maior financiamento por parte do poder público para a melhoria das condições objetivas e subjetivas de trabalho e carreira do magistério, especialmente da Educação Básica. 


\section{pro.posıções}

$e$-ISSN 1980-6248

http://dx.doi.org/10.1590/1980-6248-2017-0199

Como podemos observar, a baixa procura pelos cursos de licenciatura é evidente em todos os dados apresentados no período analisado. Quando se refere ao curso de licenciatura em Física, esses dados parecem ainda mais preocupantes. Na Tabela 2 e na Figura 2 são apresentados os dados referentes aos cursos de licenciatura em Física entre os anos de 2001 e 2015.

Tabela 2-Número de vagas, de ingressantes e de concluintes em cursos de licenciatura em Física, 2001-2015

\begin{tabular}{|l|r|r|r|r|r|}
\hline Ano & \multicolumn{1}{|c|}{ VP } & \multicolumn{1}{|c|}{ VD } & \multicolumn{1}{|c|}{ VT } & \multicolumn{1}{|l|}{ IT } & \multicolumn{1}{c|}{ CT } \\
\hline $\mathbf{2 0 0 1}$ & 2.451 & - & 2.451 & 2060 & 335 \\
\hline $\mathbf{2 0 0 2}$ & 3.233 & - & 3.233 & 2273 & 572 \\
\hline $\mathbf{2 0 0 3}$ & 3.190 & - & 3.190 & 2351 & 744 \\
\hline $\mathbf{2 0 0 4}$ & 4.131 & - & 4.131 & 2854 & 1.048 \\
\hline $\mathbf{2 0 0 5}$ & 4.701 & - & 4.701 & 2832 & 1.199 \\
\hline $\mathbf{2 0 0 6}$ & 6.889 & - & 6.889 & 3749 & 1.270 \\
\hline $\mathbf{2 0 0 7}$ & 6.907 & - & 6.907 & 3852 & 1.342 \\
\hline $\mathbf{2 0 0 8}$ & 6.523 & - & 6.523 & 3701 & 1.223 \\
\hline $\mathbf{2 0 0 9}$ & 7.257 & 4.614 & 11.871 & 6069 & 1.429 \\
\hline $\mathbf{2 0 1 0}$ & 10.630 & 6.312 & 16.942 & 7884 & 1.929 \\
\hline $\mathbf{2 0 1 1}$ & 9.893 & 5.677 & 15.570 & 8107 & 1.981 \\
\hline $\mathbf{2 0 1 2}$ & 11.755 & 4.562 & 16.317 & 8854 & 2.124 \\
\hline $\mathbf{2 0 1 3}$ & 11231 & 3.914 & 15.145 & 8378 & 1.826 \\
\hline $\mathbf{2 0 1 4}$ & 9967 & 5.479 & 15.446 & 9071 & 2.085 \\
\hline $\mathbf{2 0 1 5}$ & 10373 & 3.427 & 13.800 & 8384 & 1.919 \\
\hline Total & 109.131 & 33.985 & 143.116 & 80.419 & 21.026 \\
\hline
\end{tabular}

VP: número de vagas presenciais; VD: vagas a distância; VT: vagas totais; IT: ingressantes totais; CT: concluintes totais.

Fonte: elaborado a partir de Inep (2017).

A partir da Tabela 2, podemos observar que ao longo desses 15 anos houve grande crescimento do número de vagas e de concluintes nos cursos de licenciatura em Física - 463\% e $473 \%$, respectivamente. Sobre as modalidades de ensino, considerando todo o período analisado, 23,7\% das vagas e 10,8\% dos concluintes são provenientes de cursos EaD.

Se avaliarmos os valores numéricos apenas por sua evolução, podemos observar um crescimento de VT e de IT nos cursos de Física. No entanto, ao observarmos os números absolutos, este saldo não representa um bom panorama para a área de ensino de Física. A Figura 3 mostra os dados dos cursos de licenciatura em Física relativos ao número de vagas, ingressos e a relação ingressos/vagas. 
Figura 3 - Comportamento da taxa de ocupação de vagas, do número de vagas e do número de ingressantes nos cursos de licenciatura em Física, 2001-2015

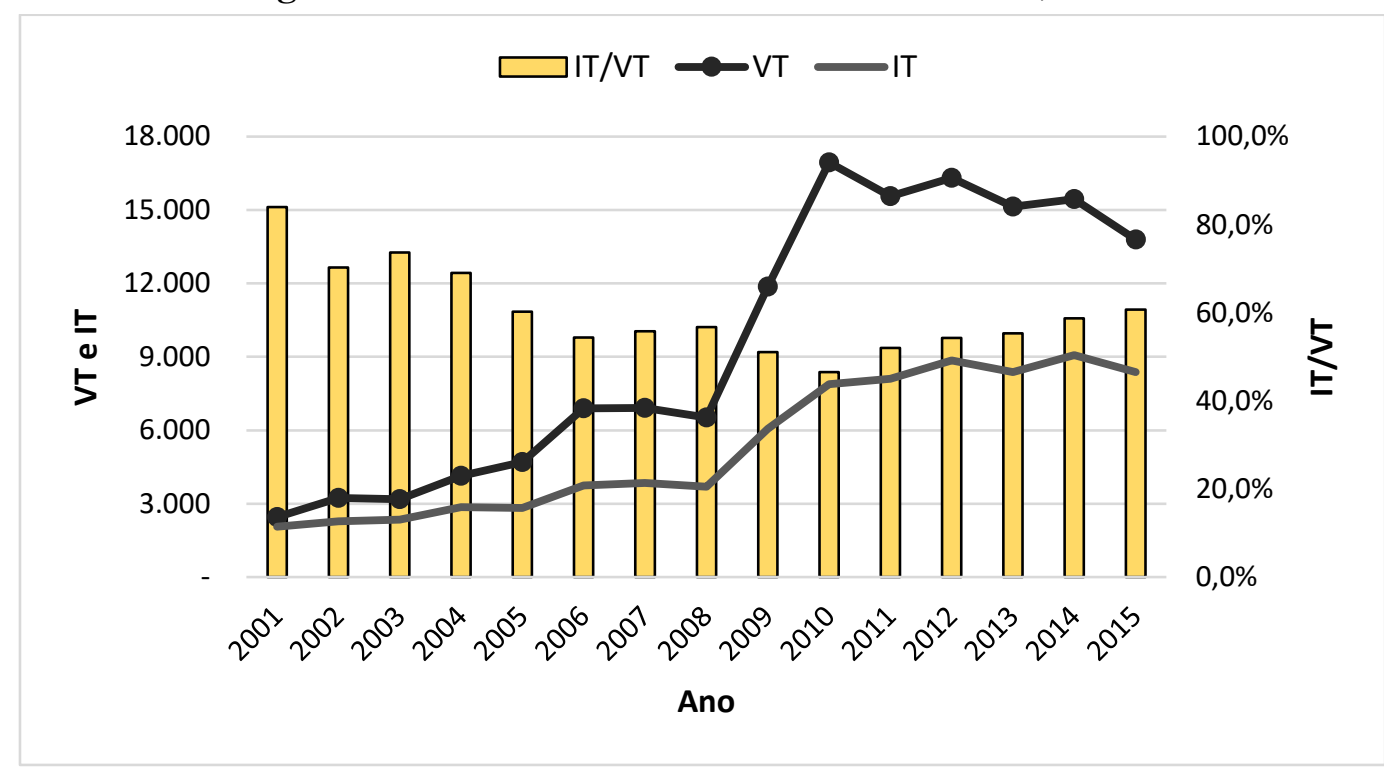

Nota: eixo esquerdo (números): vagas (VT) e ingressos (IT); eixo direito (percentual): taxa de ocupação das vagas totais ofertadas (IT/VT) nos cursos de licenciatura em Física.

Fonte: elaborado a partir de Inep (2017).

Como podemos observar, 2001 foi o ano em que ocorreu a maior taxa de ocupação das vagas, com valor de 84\%, sendo 2010 o ano de menor índice de ocupação, correspondendo a 47\% do total de vagas. Entre os anos de 2005 e 2015, a taxa de ocupação das vagas variou entre $47 \%$ e $61 \%$. Observando as curvas de vagas e ingressos, podemos notar comportamentos similares aos da Figura 2. Há um grande distanciamento entre as curvas de VT e IT a partir de 2009, com o aumento de vagas de cursos EaD. Encontramos, aqui, a mesma razão para esse comportamento: o número de vagas totais aumentou consideravelmente, enquanto o número de ingressos não cresceu na mesma proporção.

Com o intuito de comparar os dados da Física com os demais cursos, além de apresentar o número de vagas, de ingressos, de concluintes e de taxa de ocupação das vagas de cada curso de licenciatura (valores totais), na Tabela 3 é apresentada também a participação de cada curso no número geral de vagas, somando-se todos os cursos de licenciatura selecionados (VL). 
Tabela 3 - Número de vagas, percentual do número geral de vagas, número de ingressantes, taxa de ocupação de vagas e número de concluintes em cada um cursos de licenciatura selecionados, 2001-2015

\begin{tabular}{|c|r|r|r|r|r|}
\hline Cursos & VT & VT/VL & \multicolumn{1}{|c|}{ IT } & IT/VT & \multicolumn{1}{|c|}{ CT } \\
\hline Biologia & 627.743 & $11,8 \%$ & 276.395 & $44,0 \%$ & 146.517 \\
\hline Filosofia & 137.307 & $2,6 \%$ & 58.615 & $42,7 \%$ & 27.323 \\
\hline Física & 143.116 & $2,7 \%$ & 80.419 & $56,2 \%$ & 21.026 \\
\hline Geografia & 421.740 & $7,9 \%$ & 156.870 & $37,2 \%$ & 91.787 \\
\hline História & 657783 & $12,4 \%$ & 283.919 & $43,2 \%$ & 151.651 \\
\hline Letras & 2.287 .621 & $43,0 \%$ & 690.035 & $30,2 \%$ & 419.509 \\
\hline Matemática & 853.921 & $16,1 \%$ & 307.902 & $36,1 \%$ & 139.092 \\
\hline Química & 184.932 & $3,5 \%$ & 99.069 & $53,6 \%$ & 35.800 \\
\hline Geral & 5.314 .163 & $100,0 \%$ & 1.953 .224 & $36,8 \%$ & 1.032 .705 \\
\hline
\end{tabular}

VT: número total de vagas; VT/VL: proporção de vagas totais do curso/número geral de vagas dos cursos de licenciatura selecionados; IT: insgressos; IT/VT: taxa de ocupação das vagas; CT: concluintes. Fonte: elaborado a partir de Inep (2017).

A partir da Tabela 3, podemos observar que o número de vagas oferecidas nos cursos de licenciatura selecionados foi maior que 5 milhões, mas apenas 36,8\% destas vagas oferecidas no período foram preenchidas (coluna IV/VT). O curso com maior número de ingressos foi o de Letras, sendo o curso com maior número de vagas oferecidas em relação ao número geral de vagas $(43,0 \%)$, mas também com o maior percentual de vagas ociosas, tendo apenas 30,2\% de ocupação (coluna IT/VT). O curso com maior proporção de vagas preenchidas é o de Física, com 56,2\%, seguido do curso de Química, com 53,6\%. Porém, esses cursos correspondem apenas a $2,7 \%$ e $3,5 \%$ das vagas totais oferecidas, respectivamente.

A Figura 4 indica a participação de cada curso no número de ingressos e número total de concluintes dos cursos de licenciatura selecionados entre 2001 e 2015. 


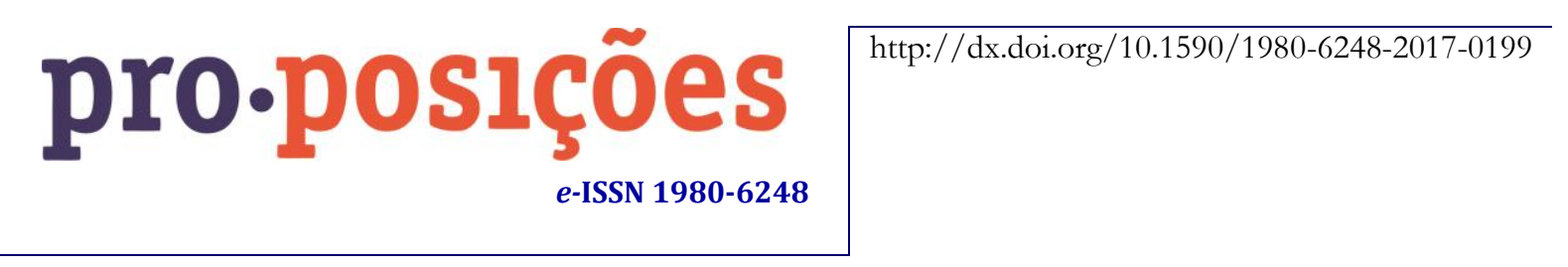

Figura 4 - Representação de cada curso no número de ingressos e concluintes entre 2001 e 2015

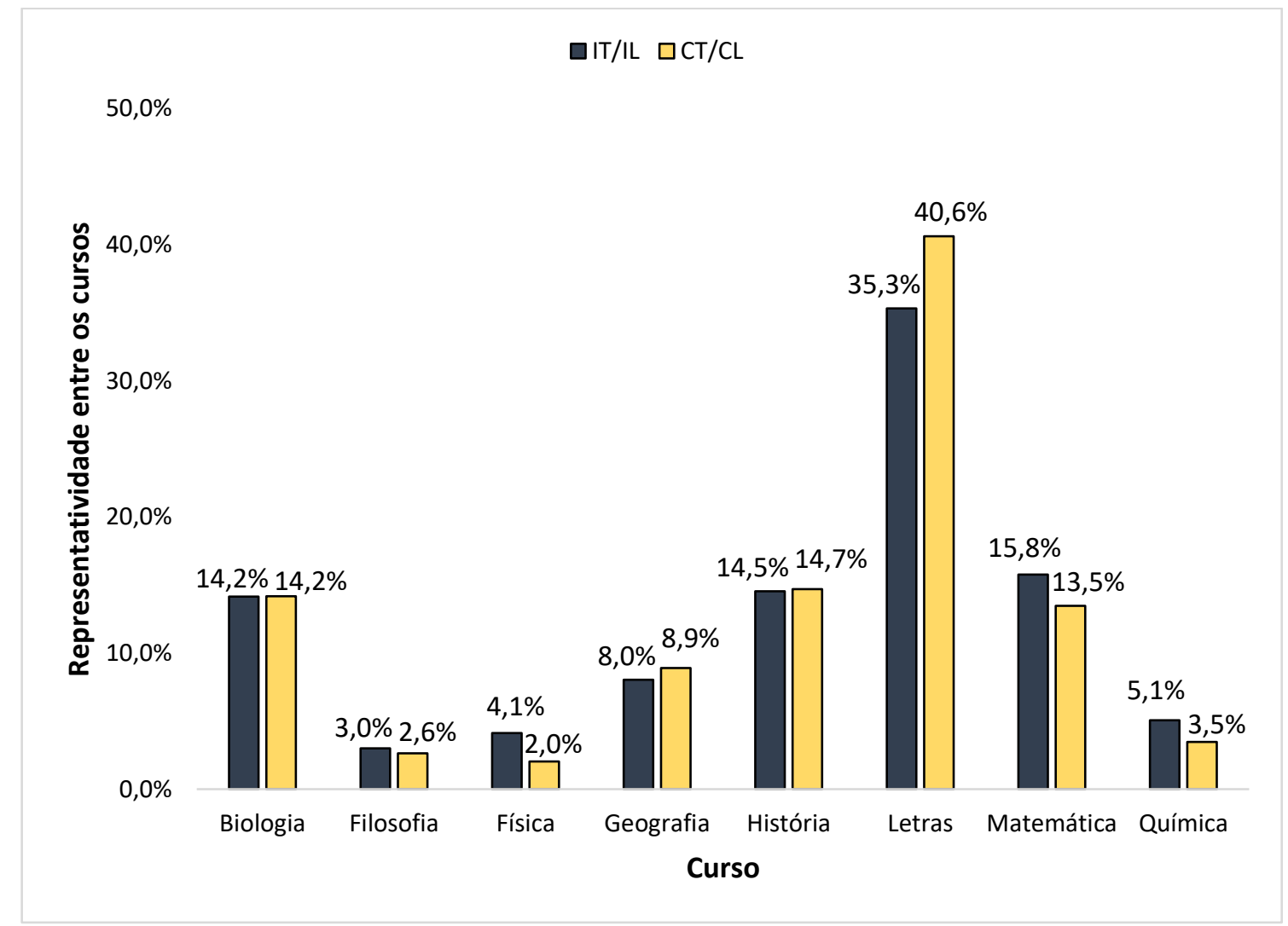

Nota: razão entre o número de ingressos de cada curso (presencial e a distância) pelo número de ingressos totais nos cursos de licenciatura selecionados (IT/IL) e razão entre o número de concluintes de cada curso

(presencial e a distância) pelo número de concluintes totais nos cursos de licenciatura selecionados (CT/CL).

Fonte: elaborado a partir de Inep (2017).

Alguns cursos nesse período de análise possuem maior representatividade de concluintes do que de ingressos. Isto se deve ao fato de que os concluintes não são necessariamente os mesmos que ingressaram neste período. Há neste caso concluintes que ingressaram antes de 2001 e ingressantes que ainda não concluíram o curso até 2015.

Mesmo que os concluintes entre os anos de 2001 a 2015 não sejam os mesmos ingressantes nesse mesmo período, é possível fazer uma comparação entre esses dois dados. A grande maioria dos cursos apresenta percentuais de ingressantes muito próximos de concluintes, algumas vezes maiores que os percentuais de ingressos. No entanto, o caso da Física e da Química são claramente diferentes. Dos ingressantes nos cursos de licenciatura selecionados, 5,1\% iniciam o curso de licenciatura em Química, mas dos concluintes essa taxa corresponde a 


\section{pro.posições}

http://dx.doi.org/10.1590/1980-6248-2017-0199

\section{$e$-ISSN 1980-6248}

apenas 3,5\%. A Física possui ainda maior variação: 4,1\% dos ingressos e 2,0\% dos concluintes. Deste modo, verificamos que a evasão nos cursos de Física parece ser maior em relação a todos os demais cursos analisados, o que reflete diretamente no considerável déficit de professores formados nessa área do conhecimento para atuação na educação básica.

Essa realidade pode ser explicada por diferentes razões, as quais necessitam ser investigadas por estudos mais específicos e aprofundados para cada contexto. Todavia, a partir das pesquisas que vêm sendo realizadas sobre essa temática no Brasil (Alvarenga et al., 2012; Caôn e Frizzo, 2010; Costa \& Dias, 2015; Gatti \& Barreto, 2009; Louzano et al., 2010; Rosa, 2014), podemos inferir que entre essas razões está a fragilidade da Educação Básica que, também por diferentes motivos, não têm se apresentado como uma base sólida para garantir aos estudantes sua permanência nos cursos de graduação.

Como já mencionamos, ações governamentais, tais como o Reuni, o Fies e a Lei n ${ }^{\circ}$ 12.711/2012, contribuíram para maior democratização do acesso ao Ensino Superior, uma vez que os jovens, especialmente os de baixa renda oriundos, em sua grande maioria, de escolas públicas, passaram a ter melhores oportunidades de concorrer a vagas nas universidades com estudantes de classe alta que, tendo realizado seus estudos majoritariamente em colégios privados, tiveram acesso a uma educação que, segundo Alvarenga et al. (2012), os prepararam para ingressar em boas universidades públicas.

Um estudo realizado por Louzano et al. (2010) indica que o Brasil tem atraído indivíduos com baixo rendimento acadêmico e com perfil socioeconômico baixo para os cursos de licenciatura. Esse dado é corroborado pela Sintese de Indicadores Sociais (SIS) do Instituto Brasileiro de Geografia e Estatísticas (IBGE) de 2014, segundo a qual os estudantes matriculados no Ensino Superior pertencentes às camadas mais baixas da população representavam, em 2004, 1,7\% e 1,3\% dos estudantes das redes de ensino pública e privada, respectivamente. Em 2013, esses números subiram para 7,2\% e 3,7\%. (IBGE, 2014), o que evidencia maior acesso dos jovens de classe baixa a cursos de graduação.

Entretanto, ampliar o acesso à educação não é o mesmo que garantir as condições de permanência e equidade para os alunos ingressantes no Ensino Superior (Caôn \& Frizzo, 2010). Pelo contrário, ampliar as oportunidades de acesso, mas não oferecer condições de permanência, pode reforçar as desigualdades históricas e sociais que têm marcado a trajetória do Ensino Superior. A evasão no Ensino Superior e, mais especificamente, nos cursos de 


\section{pro.posıções}

http://dx.doi.org/10.1590/1980-6248-2017-0199

\section{$e$-ISSN 1980-6248}

licenciatura pode ser resultado, também, das dificuldades encontradas por muitos estudantes que, por não terem estabelecida uma rotina de estudos e de tempo dedicado às atividades acadêmicas (seja por condições subjetivas ou objetivas), encontram dificuldades em prosseguir na vida acadêmica (Costa \& Dias, 2015). Segundo Rosa (2014), os estudantes, especialmente aqueles oriundos de escolas públicas, ao iniciarem sua trajetória no Ensino Superior, podem se deparar com algumas barreiras devido à condição deficiente de sua formação básica.

Essa deficiência na formação básica fica evidente se analisarmos os dados de indicadores nacionais como a Avaliação Nacional do Rendimento Escolar, popularmente conhecida como Prova Brasil, uma das avaliações que compõem o Sistema Nacional de Avaliação da Educação Básica (Saeb). A Prova Brasil é uma avaliação realizada com alunos do $5^{\circ}$ e $9^{\circ}$ anos do Ensino Fundamental e $3^{\circ}$ ano do Ensino Médio e abrange todas as escolas públicas que possuam, no mínimo, 20 alunos matriculados nas séries/anos avaliados. É uma prova censitária bianual que avalia as habilidades e o desempenho dos alunos nas disciplinas de Português - com foco na leitura - e Matemática - com foco na resolução de problemas. Trata-se de uma avaliação desenvolvida pelo Inep que tem o objetivo de estabelecer o diagnóstico da Educação Básica e avaliar a qualidade do ensino oferecido pelo sistema educacional brasileiro (Inep, 2014).

Os resultados do Saeb de 2015 indicam que a proficiência média nacional dos estudantes em matemática, por exemplo, é de 219,3 (nível 4 - básico) em face de uma meta de 225 no $5^{\circ}$ ano ${ }^{3}$ (Inep, 2016b). Essa média indica que esses estudantes saem dos primeiros anos do Ensino Fundamental sem saber: reconhecer a planificação de um cubo entre um conjunto de planificações apresentadas, converter mais de uma hora inteira em minutos, determinar o resultado da multiplicação de um número inteiro por um número representado na forma decimal e resolver problemas no sistema monetário nacional envolvendo adição e subtração de cédulas e moedas, conteúdos que integram o nível 5 (acima de 225), no qual os alunos seriam considerados proficientes em Matemática nessa etapa do Ensino Fundamental (Inep, 2014).

\footnotetext{
3 Para auxiliar na interpretação dos dados da Prova Brasil, o Inep disponibilizou, no ano de 2014, uma Nota explicativa dos resultados da prova de 2013. A nota apresenta as portarias normativas, a metodologia utilizada, o processo de aplicação das provas e uma explicação para análise e interpretação dos resultados. Para essa análise, o documento traz as escalas de proficiência com os níveis que os alunos alcançaram - de acordo com a pontuação obtida no exame - e os conteúdos explorados em cada nível. Por exemplo, de acordo com a escala de proficiência em Matemática no $5^{\circ}$ ano, o aluno que atinge entre 125 e 150 pontos se enquadra no nível um, sendo capaz de "determinar a área de figuras desenhadas em malhas quadriculadas por meio de contagem" (Inep, 2014, p. 18). A partir desse documento, conseguimos analisar os resultados obtidos na Prova Brasil do ano de 2015 para o $5^{\circ}$ e $9^{\circ}$ anos do Ensino Fundamental e para o $3^{\circ}$ ano do Ensino Médio.
} 


\section{pro.posições}

http://dx.doi.org/10.1590/1980-6248-2017-0199

\section{$e$-ISSN 1980-6248}

Para os estudantes do $9^{\circ}$ ano, os índices parecem um pouco piores. Com 255,8 pontos, esses estudantes encontravam-se, em 2015, no nível 3, apresentando também um nível básico de aprendizagem em Matemática (Inep, 2016b). De acordo com as escalas nacionais de proficiência, essa média indica que os estudantes concluem o último ano do ensino fundamental sem dominar conteúdos importantes para dar prosseguimento aos estudos, tais como: localizar um ponto em um plano cartesiano a partir de suas coordenadas, converter unidades de medidas de comprimento, de metros para centímetros, determinar o valor numérico de uma expressão algébrica de primeiro grau envolvendo números naturais e localizar números inteiros negativos na reta numérica - conteúdos que integram o nível 4, acima de 275 pontos (Inep, 2014). Ao finalizar o Ensino Fundamental com deficiência de aprendizado na disciplina de Matemática, muitos desses estudantes poderão continuar encontrando dificuldades nesta disciplina no Ensino Médio.

No que se refere à Prova Brasil de 2015, também aplicada no $3^{\circ}$ ano do Ensino Médio, os estudantes apresentaram média nacional de 267 pontos em Matemática contra os 350 pontos para a proficiência nessa disciplina (Inep, 2016b). Essa média representa o nível 5, segundo o qual os estudantes são capazes, entre outros aspectos, de resolver equações e calcular a divisão do lucro em relação a dois investimentos iniciais diferentes (Inep, 2014).

Os resultados gerais divulgados pelo Inep sobre o Exame Nacional do Ensino Médio (Enem) de 2016 também apontam a área de Matemática e suas tecnologias com a segunda menor média de desempenho (489,5 pontos de um total de 1.000 pontos). A maior parte dos estudantes que realizaram a prova (2.430.115 participantes) alcançou notas entre 400 e 500 pontos. Dos participantes, 5.734 obtiveram nota zero, um número consideravelmente maior do que os estudantes que ficaram acima da média (3.747 participantes, que alcançaram notas superiores a 900 pontos) (Inep, 2016a).

Outro aspecto preocupante está nos conteúdos de Química, Física e Biologia, que compõem a área de Ciências da Natureza e suas tecnologias. Com a pior média geral no Enem de 2016, esta área do conhecimento apresentou 477,1 pontos de média. Ainda que um número relativamente menor de estudantes tenha zerado nessa área de conhecimento (3.109 participantes) se comparado a Matemática e suas tecnologias, o número de participantes que ficou acima da média caiu de forma drástica (632 participantes, com notas entre 800 e 900), 


\section{pro.posições}

http://dx.doi.org/10.1590/1980-6248-2017-0199

\section{$e$-ISSN 1980-6248}

sendo que nenhum participante alcançou nota superior a 900 pontos. A grande maioria (3.234.551 participantes) não passou dos 500 pontos no exame (Inep, 2016a).

Esses números de forma isolada não são muito representativos e não refletem, por si só, todo o conhecimento adquirido pelos estudantes - ou pela maioria deles - ao longo da Educação Básica, o que leva à exigência de uma análise mais rigorosa e aprofundada sobre os dados. No entanto, esses índices indicam que a maioria dos estudantes está finalizando a Educação Básica sem o conhecimento mínimo adequado em importantes áreas do conhecimento. Mas por que apresentar esses dados sobre o desempenho dos estudantes na Educação Básica ao discutir sobre a evasão nos cursos de licenciatura?

Segundo Louzano et al. (2010), a pesquisa educacional tem demonstrado de forma consistente que a maior parte da variação do desempenho dos alunos deve-se à base de conhecimento adquirida anteriormente ao Ensino Superior, bem como às características de sua família e comunidade. Ao analisar os dados do Enem de 2005, esses autores identificaram que cerca de um terço dos estudantes interessados na carreira docente estão entre os que possuem pior desempenho nas diferentes disciplinas do Ensino Médio. O mesmo pode ser observado nos estudos realizados por Vaillant (2006) e Gatti \& Barreto (2009), os quais indicam que um número expressivo de estudantes que optam pela licenciatura provém de classes sociais desfavorecidas econômica e culturalmente, estudou em escolas públicas, apresenta baixo desempenho em avaliações, é trabalhador e, muitas vezes, faz parte da primeira geração da família a ingressar no Ensino Superior. Sem o domínio dos conteúdos necessários para dar continuidade aos estudos, ao ingressar em um curso universitário, muitos desses estudantes podem enfrentar algumas dificuldades nos estudos das diferentes disciplinas. Essas dificuldades, aliadas a vários outros aspectos, podem levar esses estudantes ao desânimo com o curso, com a universidade e consigo mesmo, tornando-os suscetíveis a evadir. Um exemplo disso pode estar ocorrendo no curso de licenciatura em Física que, como apontado neste trabalho, possui maior taxa de evasão se comparado a outros cursos de licenciatura. Assim, embora não se possa fazer inferências sobre o real desempenho dos alunos de licenciatura em instituições de Ensino Superior apenas com base nos índices do Saeb e do Enem, esses dados lançam luz sobre o perfil da maioria dos indivíduos atraídos para a carreira docente no Brasil e a associação entre esse perfil e seu desempenho acadêmico nos cursos de licenciatura. 


\section{pro.posições}

http://dx.doi.org/10.1590/1980-6248-2017-0199

\section{$e$-ISSN 1980-6248}

Ademais, por tratarmos neste trabalho de cursos de formação de professores especificamente, podemos apontar outra possível causa igualmente prejudicial para a baixa procura e alta taxa de evasão nos cursos de licenciatura: a ausência de uma política ampla, global e sistemática de desenvolvimento profissional docente.

A Resolução n ${ }^{\circ}$ 2, de $1^{\circ}$ de julho de 2015, que define as Diretrizes Curriculares Nacionais para a formação inicial em nível superior e para a formação continuada, apresenta, com base nos estudos desenvolvidos pelo Inep sobre o perfil da docência no Ensino Médio regular, também publicados em 2015, alguns indicadores sobre a formação de professores no Brasil. Segundo esses estudos, do total de docentes que lecionam Física no Ensino Médio regular (50.543), 27,1\% lecionam apenas Física e 72,9\% lecionam Física e outras disciplinas, especialmente Matemática. Os dados evidenciam ainda que, dos professores que lecionam apenas Física e que atuam exclusivamente no Ensino Médio, 49,6\% não possuem formação específica na área. Se forem considerados os docentes que lecionam Física e outras disciplinas nesse mesmo nível de ensino, esse percentual sobe para 84,8\% do total ("Parecer CNE/CP", 2015).

Todavia, como analisado neste artigo, o problema da falta de professores de Física - e de todas as demais disciplinas - no Brasil não está relacionado, necessariamente, a falta de vagas oferecidas em cursos de licenciatura, mas, sim, ao baixo número de ocupação e de egressos desses cursos, especialmente na licenciatura em Física. Essa discrepância entre número de vagas, número de ingressos e taxa de ocupação pode estar refletindo outro problema, ainda maior e mais crônico: o da ausência de uma política ampla, global e sistemática de formação de professores no Brasil que contemple não apenas oportunidades de acesso dos jovens aos cursos de licenciatura mas, acima de tudo, condições objetivas e subjetivas de formação, trabalho e carreira que sejam adequadas e atrativas a esse público e aos professores que já se encontram na rede pública e privada de ensino.

Como já discutimos, a escassez de professores no Brasil configura-se como um problema conjuntural e crônico, produzido historicamente pela desresponsabilização do Estado pela manutenção da educação pública, gratuita e de qualidade. De acordo com Freitas (2007), as condições do trabalho pedagógico na escola - em especial na escola pública - demandam alto investimento público em políticas que as melhorem na prática. Segundo a autora, não parece coerente projetar uma formação com níveis de exigência que correspondam à importância do 


\section{pro.posıções}

http://dx.doi.org/10.1590/1980-6248-2017-0199

papel do professor sem considerar, por exemplo, a necessidade de associá-la a adequadas e satisfatórias condições de trabalho e a uma carreira que seja atraente e que estimule investimento pessoal e profissional.

Como apontam os dados analisados nesse trabalho, o número de estudantes que optam ainda hoje pela licenciatura nas instituições de Ensino Superior evidencia a potencialidade desses jovens na direção da profissão docente (Freitas, 2007). Todavia, as ações propostas pelo Estado para o desenvolvimento da formação inicial e continuada de professores da Educação Básica não parecem, em sua maioria, estar contribuindo para a superação da realidade vivenciada nas escolas públicas, mas tão somente para as mascarar (Deimling, 2014). Pensamos que a ausência de ações e medidas mais amplas, conjunturais e concretas pode desestimular os estudantes na escolha e permanência nos cursos de licenciatura e na opção pela carreira docente.

\section{Considerações finais}

Os resultados dos indicadores sobre a formação de professores no Brasil, da maneira como se encontram discutidos neste trabalho, apresentam elementos analíticos importantes sobre a formação de professores e as perspectivas para o campo, uma vez que problematizam dados relevantes sobre como tem se dado o aproveitamento dos cursos de licenciatura das instituições públicas de Ensino Superior no Brasil, bem como permitem considerar os possíveis motivos que justificam esse cenário. Tal estudo, aliado a outros que debatem essa temática, pode configurar-se numa importante base de dados para a discussão e o delineamento de políticas nacionais que, pactuadas a partir de uma coordenação orgânica, sistemática e articulada, possam não apenas indicar os rumos, mas também oferecer as condições para que os estudantes possam ingressar, permanecer e concluir os cursos de formação de professores no Brasil, bem como ingressar e permanecer nessa profissão.

A partir dos resultados obtidos, podemos observar que entre os cursos analisados, a formação em Física é a que se encontra em estado mais crítico em se tratando de número de professores formados. Entre os fatores que podem estar influenciando este baixo número de professores formados em Física, podemos destacar: (i) alta taxa de evasão, (ii) baixo número de vagas ofertadas em relação aos demais cursos de licenciatura, e (iii) baixa procura por cursos de licenciatura, haja vista, entre outras e variadas razões, a não atratividade da carreira docente. 


\section{pro.posıções}

http://dx.doi.org/10.1590/1980-6248-2017-0199

\section{$e$-ISSN 1980-6248}

Certamente, o número de vagas ofertadas é um fator relevante para a formação de novos professores, uma vez que, havendo mais vagas, estes cursos estariam mais acessíveis geograficamente aos estudantes - quanto mais universidades oferecerem cursos de licenciatura, mais pessoas poderão ter a oportunidade de os cursar e concluir. Todavia, a ampliação do acesso ao Ensino Superior, isoladamente, não favorece a formação de novos professores. Pensamos que o problema da evasão nos cursos de licenciatura envolve variados aspectos e condições e, como tal, não pode ser solucionado por meio de medidas emergenciais, isoladas e paliativas.

Aliada ao acesso - essencial para uma maior democratização da educação - faz-se necessária uma política nacional docente que inclua, necessariamente, maior financiamento por parte do poder público na melhoria das condições de permanência e apropriação do conhecimento por parte dos estudantes nas instituições de Ensino Superior, o que envolve tanto aspectos financeiros quanto de base de conhecimento anterior ao ingresso no Ensino Superior. Da mesma forma, é necessário investir em melhores condições objetivas e subjetivas de trabalho e carreira docente tendo em vista promover, além de uma formação de qualidade, condições mínimas e o suporte humano e material necessário para a atuação desse profissional nas escolas, bem como sua melhor valorização social. Com essa política ampla e global, questões relacionadas ao baixo aproveitamento das vagas e à alta evasão nos cursos de licenciatura especificamente em Física - também poderiam ser mais bem solucionadas e superadas.

Todavia, na contramão de uma política de valorização do magistério, foi aprovada em 2017 a Lei n ${ }^{\circ}$ 13.415, proposta pelo próprio governo federal para reformar o Ensino Médio. Entre as mudanças propostas que alteraram a Lei de Diretrizes e Bases da Educação Nacional (Lei no 9.394/1996) está a inclusão do Notório Saber como profissional da Educação. Essa inclusão de um profissional sem formação pedagógica (sem diploma de licenciado) para atuar na Educação Básica pode trazer grande prejuízo para a perspectiva de uma política nacional de formação docente, para a carreira docente, para as condições de trabalho e para a formação dos estudantes, levando à desvalorização da formação oferecida pelos cursos de licenciatura.

O notório saber representa a isenção do Estado de sua responsabilidade com as políticas públicas de formação e valorização da carreira docente. Essa medida, tendo em vista resolver de maneira paliativa o problema do déficit de professores, retira a responsabilidade do Estado de propor medidas efetivas para valorização e aumento da atratividade da profissão. Com isso, negam-se os reais problemas da educação e enfatiza-se o descaso com a formação de professores 


\section{pro.posıções}

http://dx.doi.org/10.1590/1980-6248-2017-0199

\section{$e$-ISSN 1980-6248}

para atuar na Educação Básica, comprometendo sobremaneira a qualidade de ensino ofertado, especialmente na educação pública.

Certamente a qualidade da educação e a valorização do magistério não dependem apenas da formação do professor. Outros elementos têm peso igualmente importante, tais como a valorização social e financeira da profissão, as condições objetivas de trabalho, as formas de organização do trabalho e da gestão escolar, as políticas públicas de educação e de financiamento, entre outros. Todos esses fatores devem fazer parte de uma política educacional ampla, orgânica e global, não devendo ser desconsiderados no delineamento de uma política nacional de formação docente.

Sabemos das limitações do presente estudo, que tem como ponto de análise apenas os dados estatísticos divulgados pelo Inep, os quais nos possibilitaram, com base nos estudos já produzidos sobre o tema, tecer algumas discussões e considerações a respeito do baixo aproveitamento de vagas nos cursos de licenciatura no Brasil. Dessa forma, este trabalho não esgota ou encerra o debate e a reflexão sobre a baixa ocupação de vagas e a evasão nos cursos de formação de professores, uma vez que o problema real da evasão nesses cursos pode não estar associado somente a uma ou outra dificuldade enfrentada no percurso acadêmico - interna ou externa às instituições e aos cursos -, mas, sim, à falta de políticas que garantam, efetivamente, a permanência dos estudantes nos cursos de licenciatura e na carreira após a conclusão do curso. Todas as variáveis envolvidas nesse processo não podem ser analisadas isoladamente, mas em conjunto, a fim de que possamos enriquecer e ampliar as investigações que já vêm sendo realizadas sobre este tema e contribuir para a composição do quadro da história, do diagnóstico e dos desafios da formação de professores no Brasil.

Por esse motivo, consideramos necessário o desenvolvimento de novos estudos que busquem analisar de maneira mais aprofundada cada caso, tendo em vista diagnosticar os fatores que têm desencadeado o baixo aproveitamento de vagas e a evasão em cada contexto específico, bem como propor caminhos para a superação dessa realidade e do problema crônico da falta de professores em nosso país. Da mesma forma, é importante o desenvolvimento de pesquisas que possam investigar, também com base nas ideias, percepções e concepções dos próprios sujeitos envolvidos no processo, outras e variadas realidades e condições que têm resultado nas altas taxas de evasão no Ensino Superior, tendo em vista a criação de propostas de ação que possam contribuir para a solução deste problema. 


\section{pro.posıções}

http://dx.doi.org/10.1590/1980-6248-2017-0199

$e$-ISSN 1980-6248

Apesar das limitações do estudo, consideramos que ele acrescenta dados, análises e discussões relevantes às pesquisas já existentes sobre a formação de professores. Um artigo dessa natureza, aliado a outros trabalhos que discutem a Educação de modo geral e a formação de professores de modo particular, pode propiciar elementos consistentes para compreensão do complexo cenário da formação e do exercício profissional docente e, desse modo, para o estabelecimento de políticas que visem às melhorias necessárias desse cenário.

\section{Referências}

Alvarenga, C. F., Sales, A. P., Costa, A. D., Costa, M. D., Veroneze, R. B., \& Santos, T. L. B. (2012). Desafios do Ensino Superior para estudantes de escola pública: um estudo na UFLA. Revista Pensamento Contemporâneo em Administração, 6(1), 55-71.

Caôn, G. F., \& Frizzo, H. C. F. (2010). Acesso, equidade e permanência no Ensino Superior: desafios para o processo de democratização da educação no Brasil. Vertentes, 19(2), 1-15.

Costa, S. L., \& Dias, S. M. B. (2015). A permanência no ensino superior e as estratégias institucionais de enfrentamento da evasão. Jornal de Politicas Educacionais, 9(17-18), 51-60. doi:10.5380/jpe.v9i17/18.38650

Deimling, N. N. M. (2014). Programa Institucional de Bolsa de Iniciação à Docência: contribuições, limites e desafios para a formação docente. Tese de Doutorado, Universidade Federal de São Carlos, São Carlos.

Ferreira, D. L. (2011). Organizaçãa para Cooperação e Desenvolvimento Econômico (OCDE) e a política de formação docente no Brasil. Tese de Doutorado, Universidade Federal do Pará, Belém.

Freitas, H. C. L. (2007). A (nova) política de formação de professores: a prioridade postergada. Educaşão \& Sociedade, 28(100, esp.), 1203-1230.

Gatti, B. A., \& Barreto, E. S. S. (2009). Professores do Brasil: impasses e desafios. Brasília, DF: Unesco.

Gatti, B. A., Barreto, E. S. S., \& André, M. E. D. A. (2011). Políticas docentes no Brasil: um estado da arte. Brasília, DF: Unesco.

Instituto Brasileiro de Geografia e Estatística. (2014). Sintese de indicadores sociais: uma análise das condições de vida da população brasileira (Estudos \& Pesquisas: informação demográfica e 


\section{pro.posições}

socioeconômica,

n.

34).

Recuperado

de http://biblioteca.ibge.gov.br/visualizacao/livros/liv91983.pdf

Instituto Nacional de Estudos e Pesquisas Educacionais Anísio Teixeira. (2014). Nota explicativa: $\begin{array}{llll}\text { resultados Prova } 2013 . & \text { Brasil de }\end{array}$ http://download.inep.gov.br/mailing/2014/nota_explicativa_prova_brasil_2013.pdf

Instituto Nacional de Estudos e Pesquisas Educacionais Anísio Teixeira. (2016a). Enem 2016: resultado individual. Brasília, DF: Ministério da Educação. Recuperado de http://download.inep.gov.br/educacao_basica/enem/downloads/2016/apresentacao _final_resultados_2016.pdf

Instituto Nacional de Estudos e Pesquisas Educacionais Anísio Teixeira. (2016b). Sistema de Avaliação da Educação Básica: edição 2015: resultados. Brasília, DF: Ministério da Educação.

Instituto Nacional de Estudos e Pesquisas Educacionais Anísio Teixeira. (2017). Sinopses Estatísticas da Educaşão Superior: Graduação. Recuperado de http://portal.inep.gov.br/web/guest/sinopses-estatisticas-da-educacao-superior

Louzano, P., Rocha, V., Moriconi, G. M., \& Oliveira, R. P. (2010). Quem quer ser professor? Atratividade, seleção e formação docente no Brasil. Estudos em Avaliação Educacional, 21(47), 543-568. doi:10.18222/eae214720102463

Maués, O. C. (2011). A política da OCDE para a educação e a formação docente: A nova regulação? Educação, 34(1), 75-85.

Mazzeu, L. T. B. (2009). A política de formação docente no Brasil: fundamentos teóricos e epistemológicos. In Anais da 32 Reunião Nacional da Anped (pp.1-17). Associação Nacional de Pós-Graduação e Pesquisa em Educação, Caxambu.

Oliveira, D. A. (2011). A nova regulação de forças no interior da escola: carreira, formação e avaliação docente. Revista brasileira de política e administração da educação, 27(1), 25-38.

Parecer CNE/CP no: 2/2015. (2015, 25 de junho). Diário Oficial da União, seção 1, 13.

Rosa, C. M. (2014). Limites da democratização da educação superior: entraves na permanência e a evasão na Universidade Federal de Goiás. Poíesis Pedagógica, 12(1), 240-257. doi:10.5216/rpp.v12i1.31219 


\section{pro.posıções}

http://dx.doi.org/10.1590/1980-6248-2017-0199

\section{$e$-ISSN 1980-6248}

Ruiz, A. I., Ramos, M. N., \& Hingel, M. (2007). Escassez de professores no Ensino Médio: propostas estruturais e emergenciais. Brasília, DF: Ministério da Educação.

Shiroma, E. O., Moraes, M. C. M., \& Evangelista, O. (2007). Política Educacional (4a ed.). Rio de Janeiro: Lamparina.

Tardif, M. (2012). Saberes docentes e formação profissional (13a ed.). Petrópolis: Vozes.

Tartuce, G. L. B. P., Nunes, M. M. R., \& Almeida, P. C. A. (2010). Alunos do ensino médio e atratividade da carreira docente no Brasil. Cadernos de Pesquisa, 40(140), 445-477. doi:10.1590/S0100-15742010000200008

Tribunal de Contas da União. (2014). Auditoria coordenada educação: ensino médio. Brasília, DF: TCU.

Vaillant, D. (2006). Atraer y retener buenos profesionales en la profesión docente: políticas en Latinoamérica. Revista de Educación, (340), 117-140.

Submetido à avaliaşão em 20 de dez̧embro de 2017; revisado em 18 de julho de 2018; aceito para publicação em 16 de março de 2019. 